\title{
Crack path in torsion loading in very high cycle fatigue regime
}

\author{
H.Q.Xue ${ }^{1}$ and C. Bathias \\ University Paris 10/ LEME-ITMA, 50 rue de Sevres, Ville d'Avray 92410 (Fr) \\ claude@bathias.com \\ 1- presently associate professor at NWPU, XIAN, China.
}

\begin{abstract}
Torsion fatigue tests have been conducted at $20 \mathrm{kHz}$ ultrasonic fatigue testing system, and compared to the torsion fatigue data generated on $35 \mathrm{~Hz}$ conventional fatigue test machine to determine if there are any frequency effects. Failure modes and fracture surfaces in long life regime were examined and discussed. The difference in fatigue behavior and fracture mechanism under pure ultrasonic torsion loading for three kinds of alloys including cast aluminum 2-AS5U3G-Y35, D38MSV5S steel and 100C6 steel are discussed. Results indicated that the $S-N$ curves exhibit decrease in fatigue strength beyond $10^{7}$ cycles.
\end{abstract}

Keywords: Torsion fatigue; gigacycle fatigue; $20 \mathrm{kHz}$; S-N curve ; ultrasonic fatigue

\section{INTRODUCTION}

Recent work using ultrasonic test system has shown that many materials, including some steel, aluminum alloys and titanium alloys, exhibit a sharp decrease in fatigue strength between fatigue lives of $10^{6}$ and $10^{9}$ cycles [1-5]. However, it is much more difficult to carry out fatigue tests in torsion in the gigacycle regime where the fatigue life of many car components is ranging The first step is to design a good device, which is an important part of this study.

Cast aluminum AS5U3G-Y35, D38MSV5S steel and 100C6 steel are three kinds of alloys used in automotive engine components. Due to some components subjected to low amplitude, high cycle, high frequency cycle loading in their working service, it is of interest to investigate fatigue behavior and fracture mechanism of the alloys in very high cycle regime.[2] .

Structural components used in rotating parts in engines, are usually required to be designed using a lifetime failure-free criterion for a very large number of cycles, or an endurance limit. Fatigue data in tension loading are insufficient for assessing high cycle fatigue limit in torsion loading [1-2]. Thus, it is necessary to investigate the torsion fatigue performance in very high cycle regime. Since 1993, Stanzl-Tschegg S.E and et al [1] designed and constructed an ultrasonic torsion fatigue test system at a frequency of $21 \mathrm{kHz}$, it began to investigate torsion fatigue behavior of alloys. However, much of the available fatigue properties today are in axial loading. To achieve the goal of determining the fatigue strength under torsion loading, a novel piezoelectric torsion fatigue testing machine was developed, in our laboratory, in which a torsion fatigue specimen is driven into a $20 \mathrm{kHz}$ high frequency resonance mode. The SN curve, the origin of the fatigue crack, and the fatigue characteristics are discussed up to $10^{10}$ cycles.

\section{EXPERIMENT}




\subsection{Materials}

The materials used in this study were one cast aluminum 2-AS5U3G-Y35, one D38MSV5S steel and one high strength steel 100C6, having the nominal compositions as shown in Table 1.

Tab.1Chemical composition of 100C6 steel (wt\%)

\begin{tabular}{|c|c|c|c|c|c|c|c|c|c|c|c|c|c|}
\hline Material & $\mathrm{C}$ & $\mathrm{Mn}$ & $\mathrm{P}$ & $\mathrm{S}$ & $\mathrm{Si}$ & $\mathrm{Al}$ & $\mathrm{Fe}$ & $\mathrm{Mg}$ & $\mathrm{Ni}$ & $\mathrm{Cr}$ & $\mathrm{Cu}$ & Mo & V \\
\hline 2-AS5U3G-Y35 & & 0.32 & & & 5.3 & & 0.57 & 0.36 & & & 3.15 & & \\
\hline D38MSV5S & 0.384 & 1.23 & 0.012 & 0.064 & 5.67 & 0.025 & & & 0.063 & & 0.063 & 0.018 & 0.089 \\
\hline $100 \mathrm{C} 6$ & 1.03 & 0.339 & 0.012 & 0.008 & 0.242 & & & & 0.147 & 1.461 & & 0.032 & \\
\hline
\end{tabular}

Tab.2 Mechanical properties of 100C6 steel

\begin{tabular}{ccccccc}
\hline Material & $\mathrm{E} / \mathrm{GPa}$ & $\rho /{\mathrm{kg} \cdot \mathrm{m}^{-3}}^{-}$ & $\mathrm{A} /(\%)$ & $\mathrm{R}_{\mathrm{e} 0.2 \%} / \mathrm{MPa}$ & $\sigma_{\mathrm{b}} / \mathrm{MPa}$ & $\mathrm{HV} 30$ \\
\hline 2-AS5U3G-Y35 & 72 & 2700 & 1 & 182 & 222 & 99 \\
D38MSV5S & 210 & 7850 & 20 & 608 & 878 & 246 \\
100C6 & 210 & 7860 & --- & 1158 & 2300 & 780 \\
\hline
\end{tabular}

The typical microstructure in 100C6 steel is a fine martensite with small inclusion ( MnS ). The microstructure of D38MSV5S shows ferrite (50\%) and perlite (50\%). Aluminium has a typical eutectic structure with primary dendrite cells composed of eutectic silicon particles and $\mathrm{Fe}$ and /or Mg. [5]

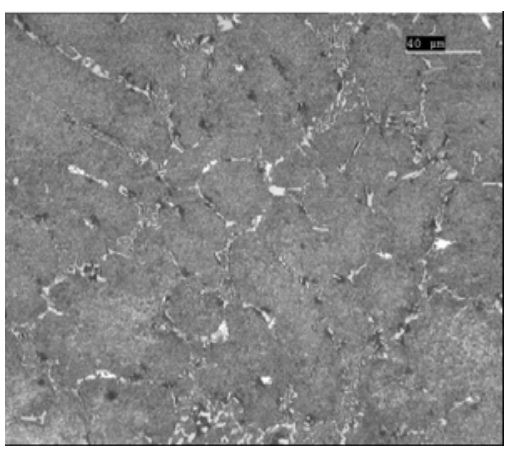

(a)

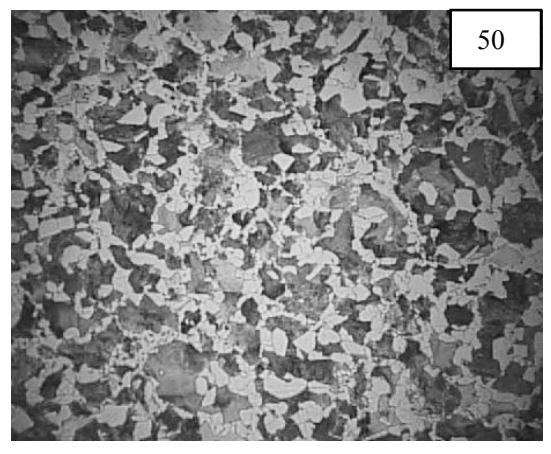

(b)

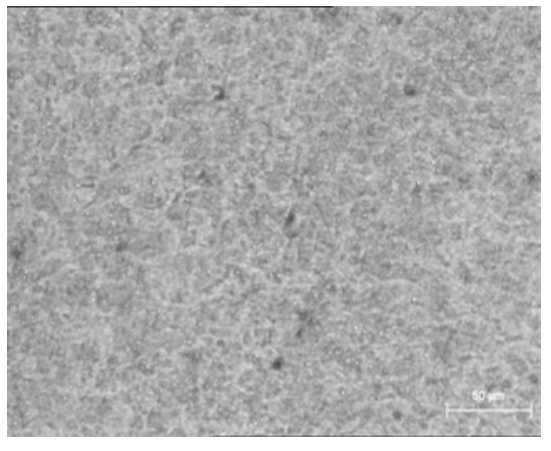

(c)

Fig.1 Microstructure of test alloys

(a) 2-AS5U3G6Y35; (b) D38MSV5S; (c) 100C6

\subsection{Experimental system}

In order to test the alloys up to $10^{10}$ cycles in torsion fatigue, an ultrasonic torsion fatigue system was designed [2-5]. The main component of the ultrasonic system is a piezoelectric transducer, which converts an electronic signal at a frequency of $20 \mathrm{kHz}$ into a mechanical displacement at the same frequency. The electronic signal is supplied by a power supply that automatically turns to the natural resonant frequency of the system. Attached to the transducer are two horn, one serves to amplify the longitudinal mechanical displacement, the other is to 
amplify the torsion angular displacement. A torsion fatigue specimen designed to run in resonance with the system is then attached to the horn. The specimens were designed so that the maximum strain is located in the gage section (shown in Fig.2).

In the study, all testing was performed at a stress ratio, $\mathrm{R}$, of -1 . Prior to each test, the strain in the gage of specimen is calibrated with a strain gage bonded to the gage section. Under the nominally elastic conditions used for loading to very high cycles, there is a linear relationship between input displacement and the strain in the gage section.. The test control software continuously records the displacement and controls the output of the power supply, therefore, indirectly controls the magnitude of the strain in the specimen.

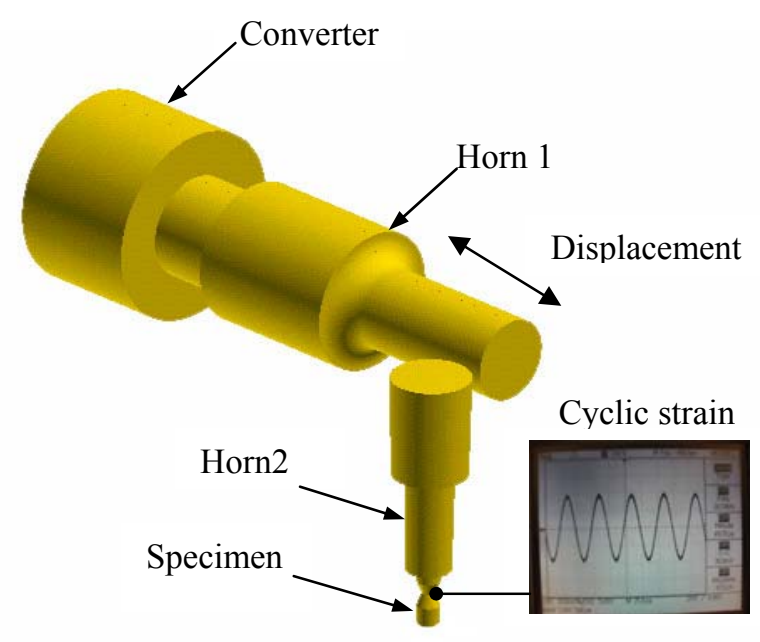

Fig.2 Ultrasonic torsion fatigue system calibration

\subsection{Testing specimen}

Three specimen sizes for different alloys used in ultrasonic torsion fatigue tests are shown in Fig.3. The dimension of torsion specimens can be determined by analytical or numerical method [2-5], the ultrasonic torsion fatigue specimen is significantly smaller than specimens used for tension-compression testing, since the wavelength of shear waves is smaller.

\subsection{Test procedure}

Torsion fatigue tests were conducted in an open environment at room temperature[5], with the stress ratio $\mathrm{R}=-1$, at $20 \mathrm{kHz}$. This leads to torsion shear loading with maximum amplitude in the centre of the specimen. The specimens were cooled with dry air during fatigue testing to decrease the temperature rise caused by internal friction of material. Failure of specimens may be detected by monitoring the resonance frequency, which makes possible the automatic operation of the experiments. That is, the test stops automatically until specimen fails, or it attain $10^{10}$ cycles. Fatigue crack initiation in the fatigue specimens was investigated using both optical microscopy and scanning electron microscope. . 


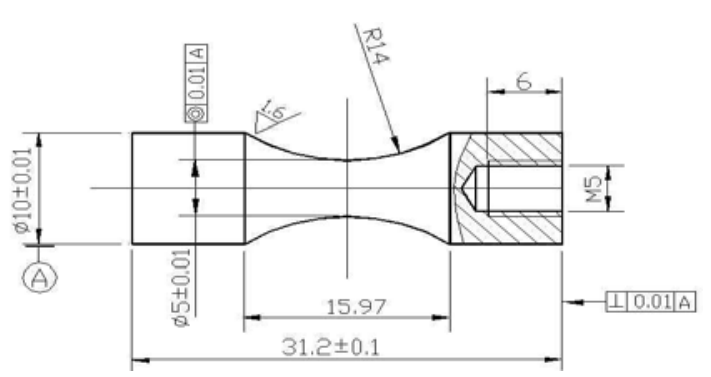

AS5U3G-Y35

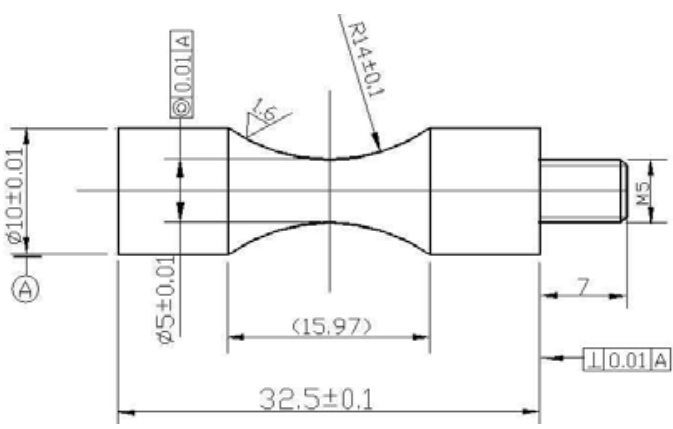

D38MSV5S steel

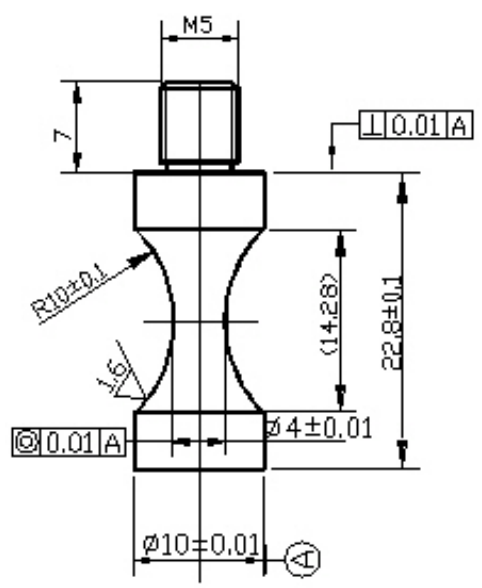

Fig.3 Dimension of ultrasonic torsion fatigue specimens

100C6

\section{EXPERIMENTAL RESULTS}

The stress-life (S-N) curves for D38MSV5S steel, AS5U3G-Y35 and 100C6 are shown respectively in Fig.4a to Fig.4c. In the figures, solid marks indicate the specimens tested at $35 \mathrm{~Hz}$, the open ones indicated that specimens tested at $20 \mathrm{kHz}$ ultrasonic torsion fatigue test machine. The S-N curves show that fatigue failure of the three alloys may occur between $10^{6}$ and $10^{10}$ cycles

For D38MSV5S steel, fatigue lifetime increases as the stress amplitude decreases in the life range of $10^{4} \sim 2 \times 10^{6}$ cycles. Stress amplitude decreases continually from $260 \mathrm{MPa}$ to $240 \mathrm{MPa}$ in the range of $2 \times 10^{6}-10^{10}$ cycles (Fig.4(a)).For AS5U3G-Y35, fatigue lifetime increases with the stress amplitude decreases in the life range of $10^{4}-10^{7}$ cycles, and fatigue fracture occurred beyond $10^{7}$ cycles, however, the slope of S-N curve looks as an asymptote after $10^{8}$ cycles (Fig. 4b). For 100C6, horizontal asymptote cannot be draw between $10^{7}$ and $10^{10}$ cycles. In spite of the scatter of the results, it is notice that the fatigue strength is decreasing from 450 $\mathrm{MPa}$ to $350 \mathrm{MPa}$ 


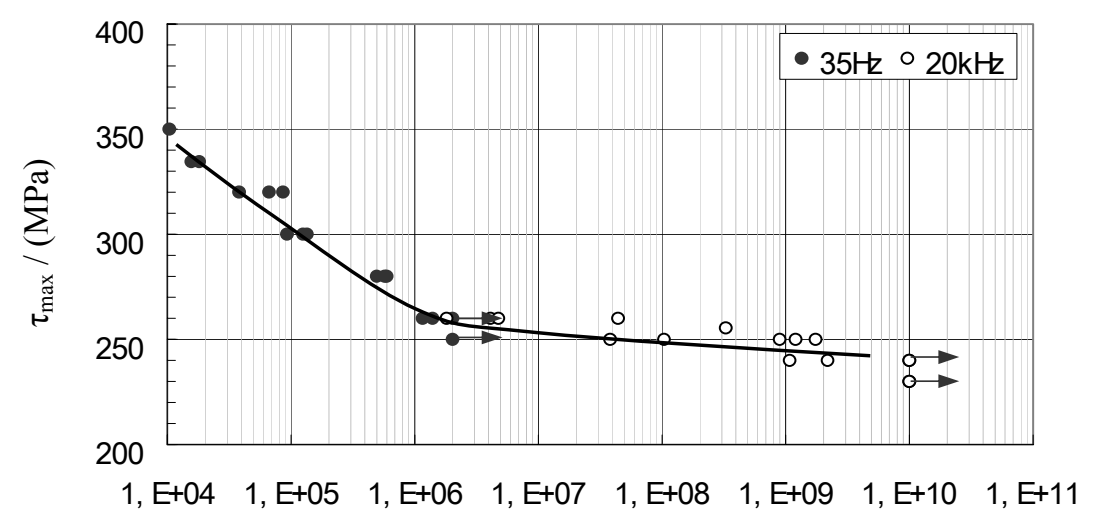

a Life / cycles

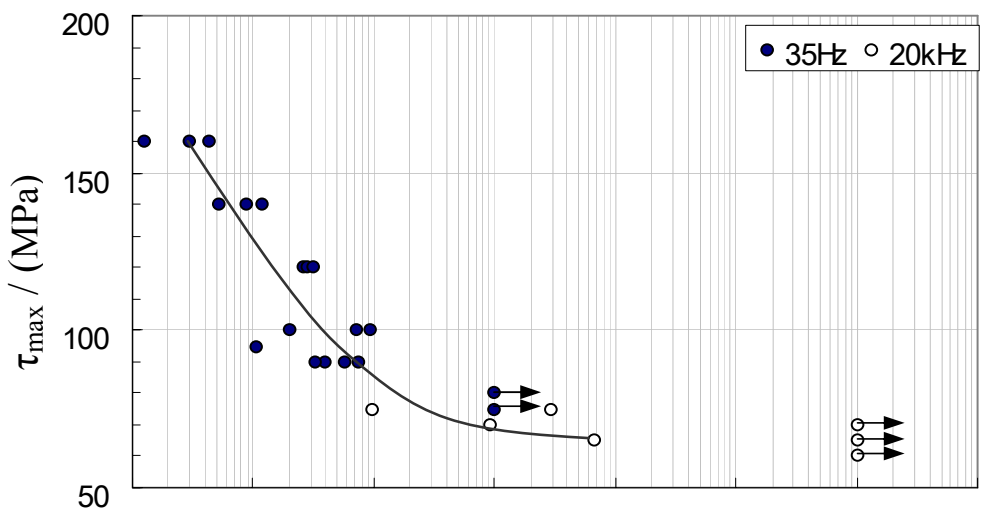

1, E+04 1, E+05 1, E+06 1, E+07 1, E+08 1, E+09 1, E+10 1, E+11 Life / (cycles)

$\mathrm{b}$

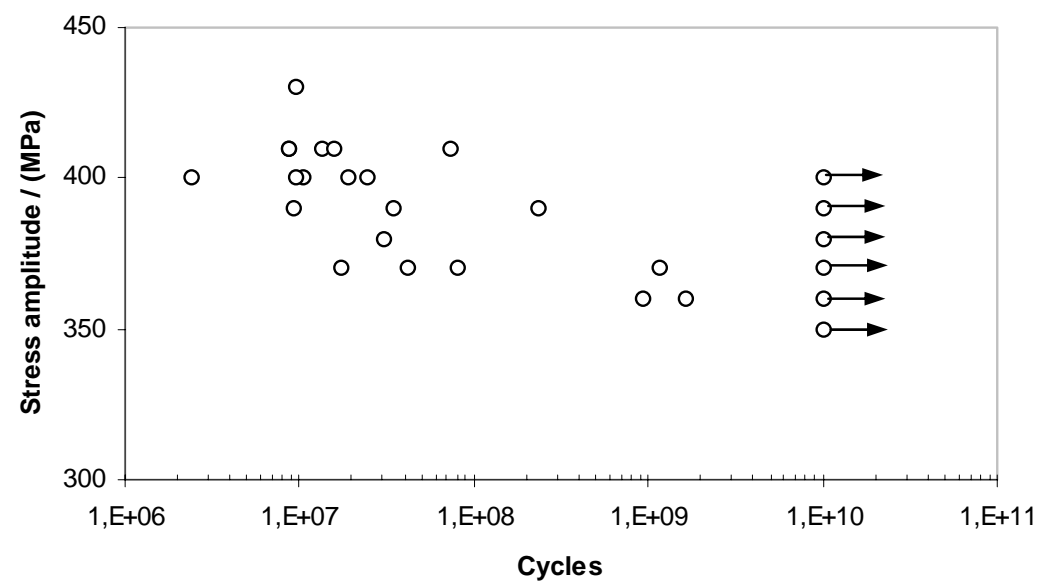

c

Fig. 4 Torsion fatigue test results $(R=-1)$

(a) D38MSV5S; (b) 2-AS5U3GY35; (c) $100 \mathrm{C} 6$ 
Generally, the S-N curves of the three alloys are continuously decreasing from the mega to the gigacycle range, although it decreases gently, the fatigue limit of these alloys defined with a statistical analysis between $10^{6}$ and $10^{7}$ cycles can not guarantee a safe design, in the gigacycle fatigue regime. The results obtained at lower frequency show that there is no evident frequency effect.

\section{FRACTURE ANALYSIS AND DISCUSSION}

\subsection{Fracture analysis}

In torsion fatigue test, [6-7] shear crack nucleation and growth are followed by crack growth on planes of maximum principal stress amplitude. Typical crack patterns observed at the surface are shown in Fig.5.But the crack initiation is not the same for the three alloys
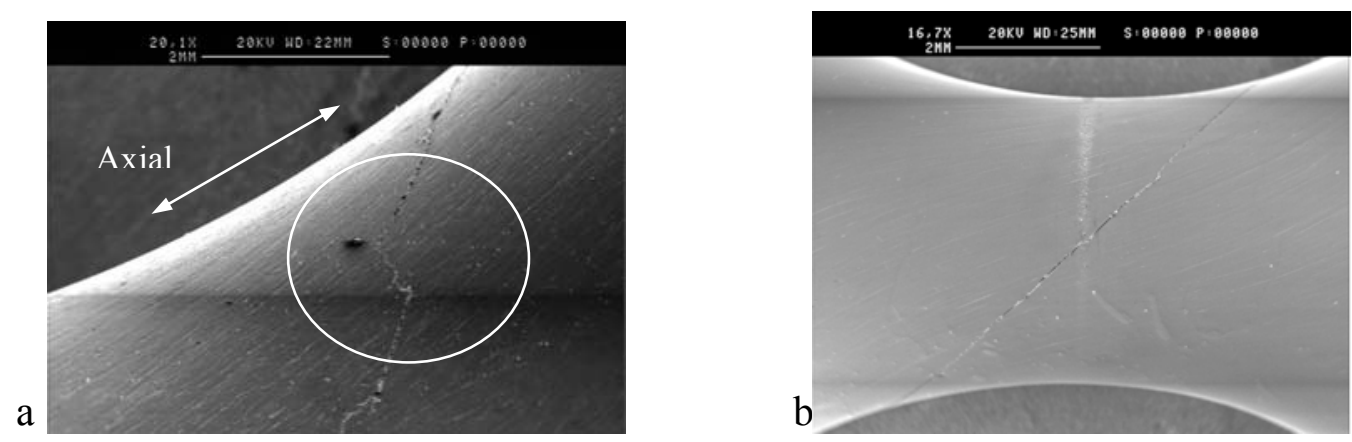

Fig.5 Torsion surface crack patterns in the failed specimen

(a) small crack initiated on the plane of maximum shear aniu propagated in $45^{\circ}$ plane;

(b) crack growth only in $45^{\circ}$ plane

Fatigue crack initiations in the gigacycle regime for D38MSV5S steel and AS5U3G-Y35 are always from the surface of specimens. As it is in axial loading, the initiation is sometime in the subsurface for aluminum alloy. ( Fig.6)

In 100C6 bearing steel; the fatigue crack initiates, as expected, from the surface at higher stress amplitudes and in subsurface or beneath the surface for longer life When the initiation starts from the interior the $\mathrm{MnS}$ inclusions are involved in the same maner that in axial loading. The subsurface crack initiation was observed in most fatigue tested samples with the fatigue life between $10^{7}$ and $10^{9}$ cycles. The fatigue fracture is a typical fish eye.. Besides, the dark zone around the inclusion the shape of the crack is more or less an ellipse, at the contrary of axial loading. [3] where the fish eye is circular.
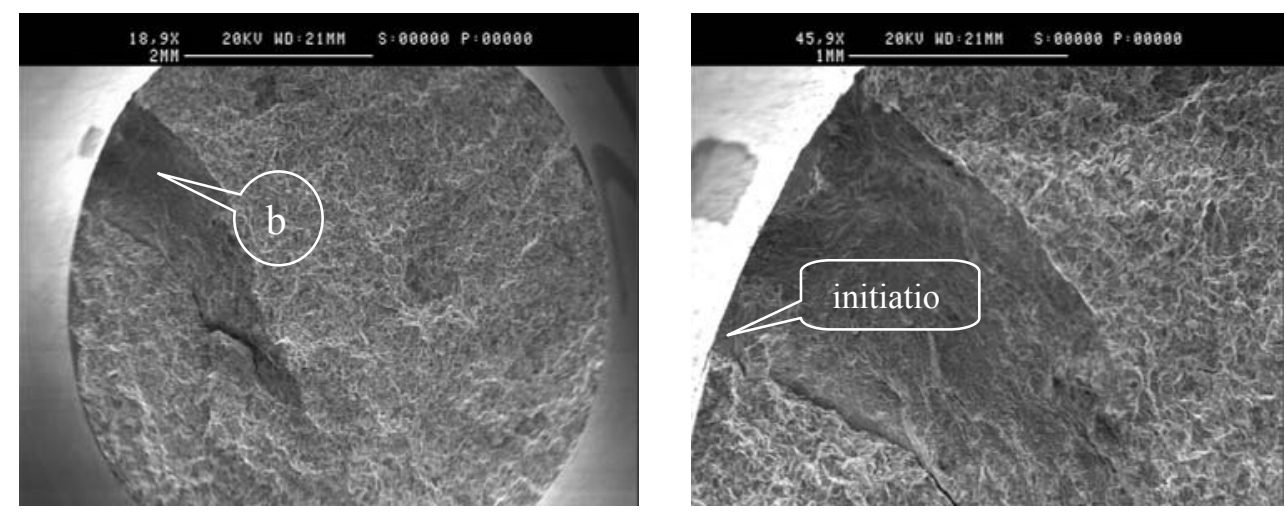


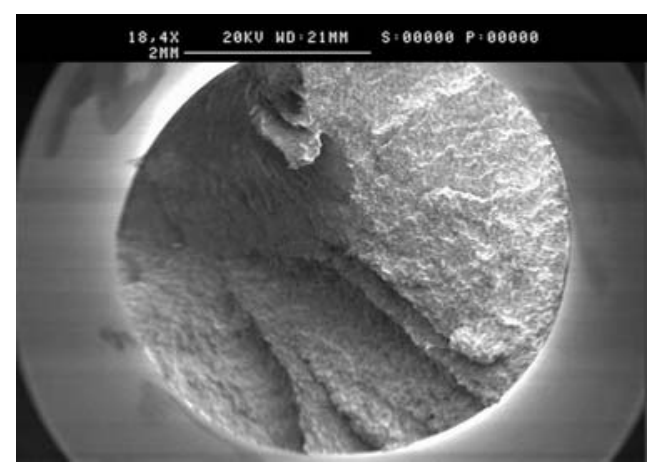

Fig. 6 Typical initiation in D38MSV5S ( $240 \mathrm{MPa} \mathrm{Nf}=6.9108$ cycles)-a-and in AS5UG (70MPa, $\mathrm{Nf}=9.510^{6}$ cycles)-b-

Fig. 7 shows a typical fracture surface at very high cycle regime, in 100C6 steel. At the center of the fish-eye, an inclusion exists and a fine granular facet region can be seen around the inclusion. This type of crack initiation was observed for fatigue fracture at $10^{9}$ cycles

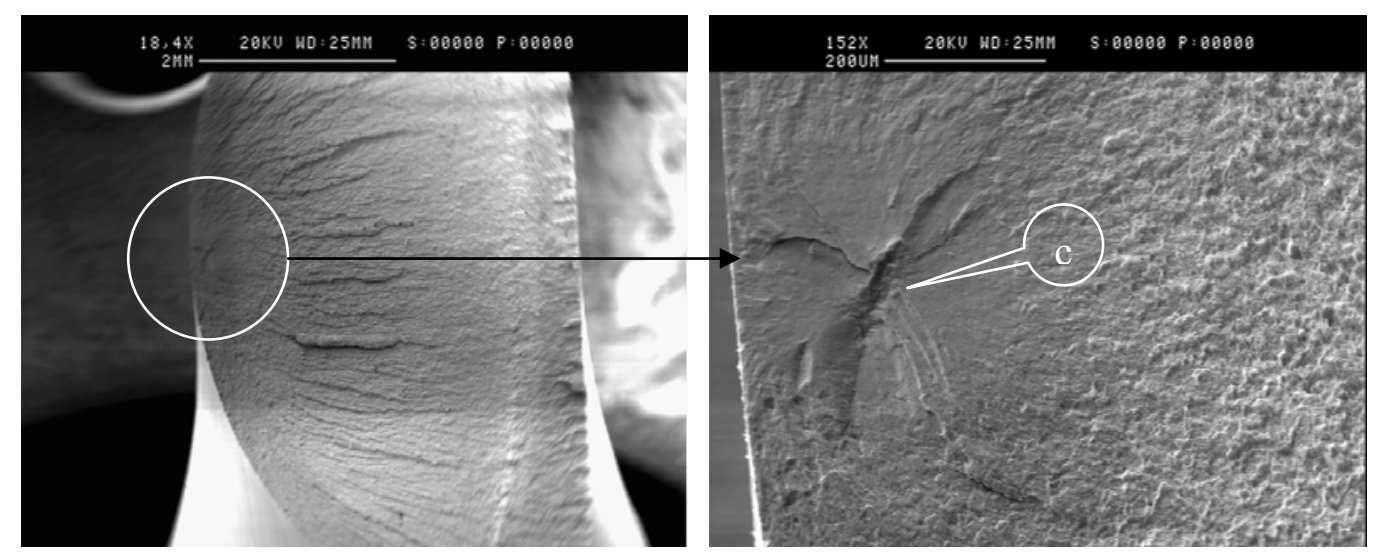

(a)

(b)

Fig.7 Fatigue crack initiationin 100C6 steel, from a subsurface inclusion in torsion (a) fatigue fracture surface; (b) fish-eye and inclusion

$$
\left(\tau_{\max }=370 \mathrm{MPa} ; \mathrm{N}_{\mathrm{f}}=3.06 \times 10^{7} \text { cycles }\right)
$$

\subsection{Discussion}

For cast aluminum AS5U3G and D38MSV5S steel, under a cyclic torsion loading, fatigue crack initiated from surface of the center of specimen where the shear stress is maximum. Fracture occurs normal to the $45^{\circ}$ tensile plane, producing a conical fracture surface, what ever is the fatigue life.

For 100C6 steel, the fatigue crack initiation location depends strongly of the number of cycles to failures. Roughly speaking, $t$ is observed that the initiation is located at the surface of the specimen when the fatigue life does not exceed $10^{7}$ cycles according to the theory. But beyond this fatigue life there is a competition between surface and internal initiation. This surprising competition is related to the high rate of inclusions in bearing steel. Those inclusions become the key parameter in gigacycle fatigue. It means that the stress concentration around a $\mathrm{MnS}$ 
inclusion induces more plasticity than the shear stress at the surface. It is also interesting to notice that the large scatter of the $\mathrm{SN}$ curve for $100 \mathrm{C} 6$ steel is probably related to the transition between two locations of the initiation.

\section{CONCLUSIONS}

Gigacycle torsion fatigue tests for three kinds of alloys used in automotive engine components have been investigated, in the paper. The following conclusion can be summarized:

(1) Fatigue failure occurs in torsion loading after $10^{7}$ cycles and up to $10^{10}$ cycles, in aluminium alloys, perlitique steel and martensitic steel.

(2) No effect of frequency was observed on the SN curve in torsion

(3) Initiation of cracks appears on the surface of the specimen at the maximum shear stress but in the bearing steel, where the inclusion rate is high, a transition occurs, entering the gigacycle regime

(4) The transition of the crack initiation from surface to subsurface in high cycle regime for $100 \mathrm{C} 6$ induces a scatter in the SN curve.

(5) Thus, a fish eye initiation can occur in torsion with an elliptical shape

\section{REFERENCES}

[1] Stanzl-Tschegg S.E., Mayer H.R., Tschegg E.K., High frequency method for torsion fatigue testing. Ultrasonic, 1993,31(4):275-280.

[2] C.Bathias. Piezo-electric fatigue testing machines and devices. In: Proceeding of the Third International Conference on Very High Cycle Fatigue. Toyko, Japan.2004:472-483.

[3] Bathias C., There is no infinite fatigue life in metallic materials. Fat. Fract. Engng Mat. Struct. 1999(22):559-565.

[4] Wang Q.Y., Berand J.Y., Bathias C., Gigacycle fatigue of ferrous alloys. Fatigue Fract Engng Master Struct, 1999,22(8):667 672.

[5] ] Xue H.Q., Explanation on gigacycle fatigue of materials in tension, bending and torsion loading. Thèse de doctorat, CNAM, 2005.

[6] D.Mcclaflin, A.Fatemi. Torsional deformation and fatigue hardened steel including mean stress and stress gradient effects. International Journal of Fatigue, 2004(26):773-784.

[7] Makabe C, Socie D. Crack growth mechanisms in pre-cracked torsion fatigue specimens

Fatigue fract Eng Mater Struct 2001(24):607-615. 